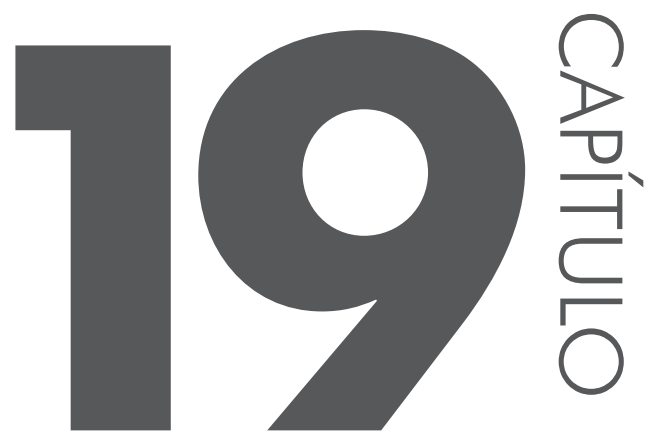

\title{
Diversidade linguística em Moçambique
}

\section{Ronaldo Rodrigues de Paula e Fábio Bonfim Duarte Universidade Federal de Minas Gerais}

\section{Introdução}

Este capítulo tem por objetivo apresentar um panorama da diversidade linguística existente em Moçambique. O país, situado na costa oriental da região austral da África, tem o português como língua oficial. No entanto, concomitantemente ao português, geralmente falado como segunda língua, coexistem várias línguas nativas essencialmente de origem bantu. $\mathrm{Na}$ África, há várias famílias linguísticas espalhadas pelo continente. Por essa razão, antes de detalharmos a complexidade linguística existente em Moçambique, este capítulo busca demonstrar quais são as principais famílias linguísticas, bem como a sua localização geográfica no continente africano. Interessa-nos demonstrar quais são as principais famílias linguísticas, bem como a sua localização geográfica no continente africano. Interessa-nos em especial lançar um olhar atento ao subgrupo bantu, tendo em conta que a pesquisa, efetuada no âmbito do Laboratório de Línguas Indígenas e Africanas (Laliafro) da UFMG, vem elaborando descrições gramaticais principalmente sobre línguas bantu faladas em Moçambique. Parte dessa produção pode ser acessada por meio do portal na internet, no endereço www.letras.ufmg. br/portal laliafro. Outro objetivo deste artigo é apresentar considerações sobre a situação linguística atual e as divergências que há em relação à distinção que se observa entre língua e dialeto. Consoante Ngunga (2004), esse problema acarreta discrepâncias em relação ao número total de línguas existentes no país. 


\section{A África e as línguas bantu}

A diversidade cultural, étnica e geográfica da África também reflete na grande diversidade linguística que o continente apresenta. Estipula-se que existam cerca de duas mil línguas nativas no continente, o que representa um quarto das línguas faladas no planeta. É importante ressaltar que as várias línguas africanas não se distribuem homogeneamente pelo continente. Nota-se que a região fronteiriça entre Camarões e Nigéria possui grande diversidade linguística. Em conformidade com Childs (2003, p. 21), pode-se afirmar que as línguas africanas apresentam vários fenômenos areais, que não são atestados em nenhum outro continente. De acordo com o autor, as línguas africanas se dividem em quatro famílias: niger-congolês, nilo-saharaniano, afro-asiático e khoisan. Na Tabela 19.1, a seguir, retirada e adaptada do trabalho de Childs (op. cit.), apresentamos (i) as principais famílias linguísticas africanas; (ii) o número total de línguas faladas em cada agrupamento; (iii) algumas línguas representativas de cada família; e, por fim, (iv) o número total aproximado em milhões de falantes dessas línguas, ${ }^{105}$ as quais possuem estatuto de língua franca em algumas regiões da África. Logo a seguir, a título de visualização e detalhamento da diversidade linguística em África, arrolamos dois mapas, que retratam a distribuição das principais famílias linguísticas africanas, conforme apresentadas na Tabela 19.1.

Tabela 19.1 - Número de línguas entre as famílias linguísticas africanas

\begin{tabular}{|c|c|c|}
\hline Famílias linguísticas & $\begin{array}{c}\text { Numero de } \\
\text { línguas }\end{array}$ & $\begin{array}{c}\text { Línguas do grupo (número de } \\
\text { falantes nativos em milhões) }\end{array}$ \\
\hline Níger-congolês & 1650 & $\begin{array}{c}\text { Bambara (3), fula (13), igbo (17), mooré } \\
(11), \text { swahili }(5), \text { yoruba }(20), \text { zulu }(9,1)\end{array}$ \\
\hline Afro-asiático (na África) & $200-300$ & $\begin{array}{c}\text { Arabic (180, all varieties), amharic (20), } \\
\text { hausa (22), oromo (10) somali (5-8), songhai } \\
(2), \text { tachelhit berber (3) }\end{array}$ \\
\hline Nilo-saharaniano & 80 & $\begin{array}{c}\text { Dinka (todos os grupos, 1,4), kanuri (4), luo } \\
(3,4), \text { maasai (883 k), nuer (840 k), phylum } \\
\text { (total 30) }\end{array}$ \\
\hline Khoisan & $30-40$ & $\begin{array}{c}\text { Nama (140 k), sandawe (70 k), kung (8-30 } \\
\text { k), !Xóó (3-4 k) }\end{array}$ \\
\hline
\end{tabular}

Fonte: Crystal (1995) apud Childs (2003).

105 Quando o número de falantes vier sinalizado com uma letra $k$, a quantidade representada estará em milhares de falantes. 


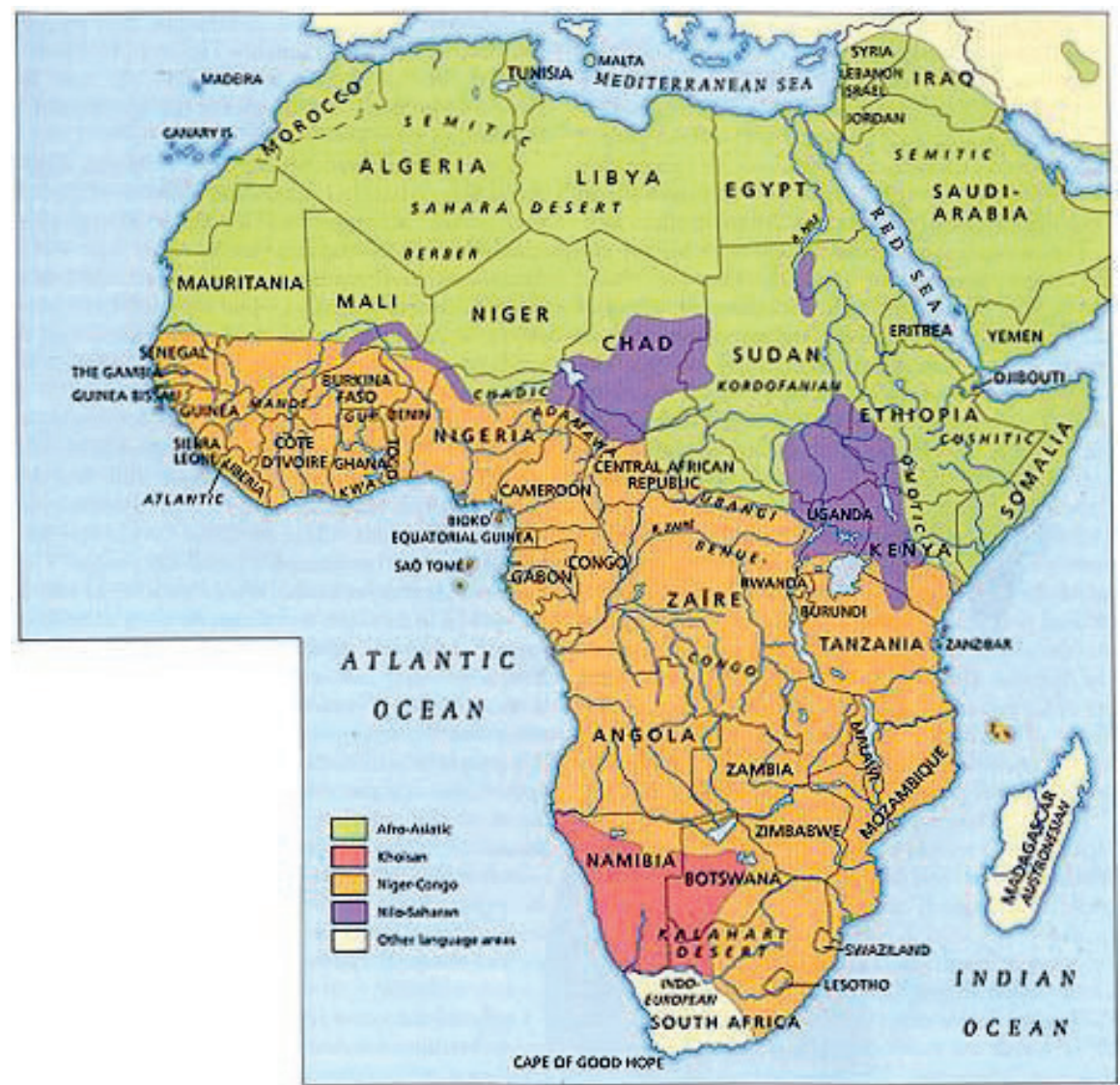

Figura 19.1 - Mapa linguístico da África. Fonte: Crystal (1995) apud Childs (2003). 


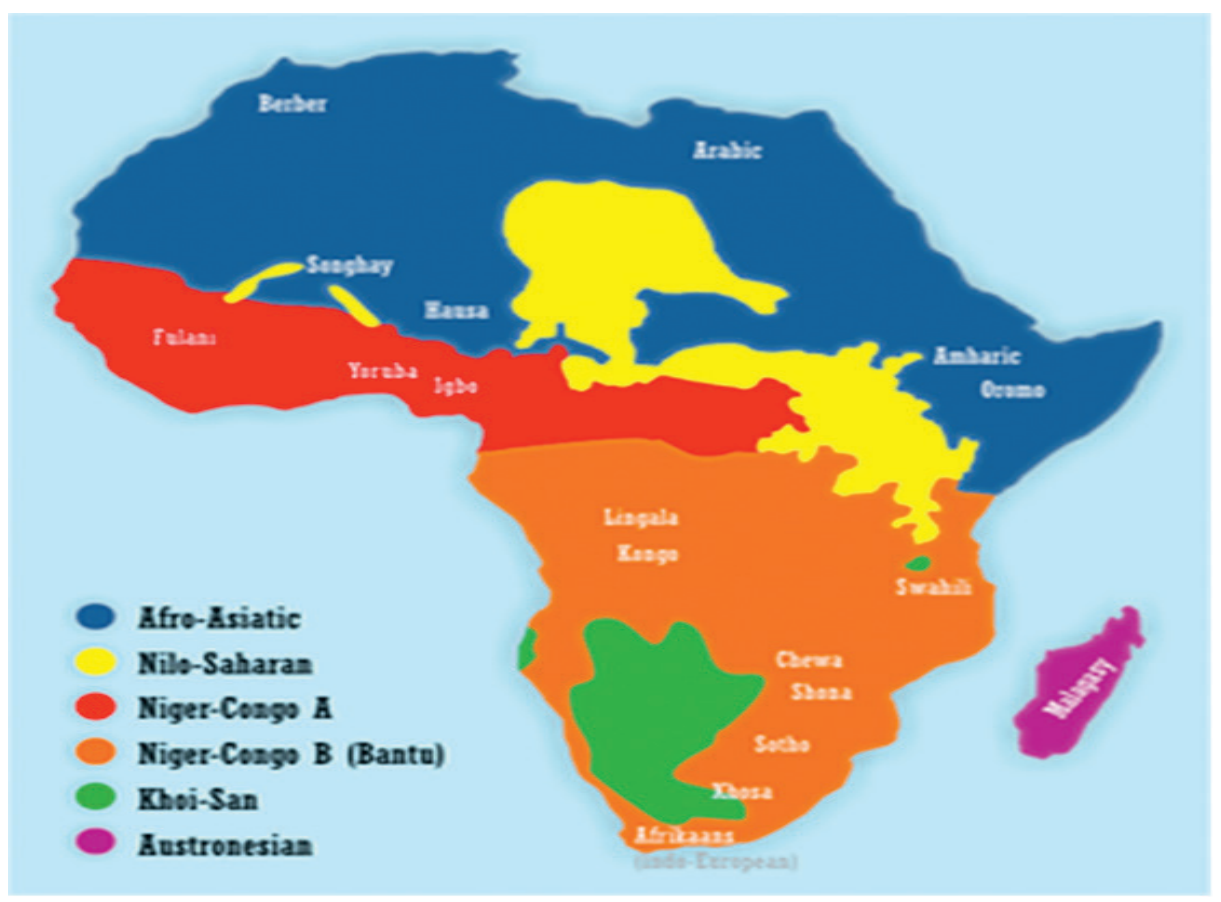

Figura 19.2 - Mapa linguístico da África. Fonte: https://upload.wikimedia.org/wikipedia/commons/f/fe/Familias de lenguas de Africa 2.png. Acesso em: 17 ago. 2016.

Conforme se vê nos mapas acima, as línguas classificadas como línguas bantu constituem uma subdivisão do ramo das línguas níger-congolesas da família niger-kordofaniana, de acordo com a classificação proposta por Greenberg (1966). São faladas principalmente na região subsaariana da África, ocupando grande parte da África meridional, central e oriental. Mais precisamente, acompanhando a proposta de Lwanga-Lunyiigo e Vansina (2010, p. 169), podemos afirmar com certa segurança que essas línguas ocupam uma região que cobre a "fronteira marítima nigero-cameruniana, no Oeste, até o litoral fronteiriço somálio-queniano, no Leste, e a partir desse ponto até as proximidades de Port-Elizabeth, no Sul”.

O Atlas das linguas do mundo (1999), citado em Nurse e Philippson (2003), afirma, à época de sua edição, que mais da metade dos cerca de 750 milhões de africanos eram falantes de línguas niger-congolesas, e aproximadamente um em cada três africanos falam línguas bantu. Em conformidade com Greenberg (2010), as línguas da família niger-kordofanianas se subdividem em dois ramos principais. $\mathrm{O}$ níger-congo, mais abrangente, com ampla extensão geográfica de falantes de suas línguas pela África subsaariana, e o kordofaniano, localizado essencialmente na região do Kordofan, no Sudão (conforme mostra a Figura 19.3, a seguir). Segundo o autor, um traço gramatical bastante saliente nas línguas dessa 
família linguística é a maneira por meio do qual os nomes, adjetivos e pronomes são organizados em classes nominais, as quais provocam intensos efeitos nas morfologias de concordância nominal e verbal.

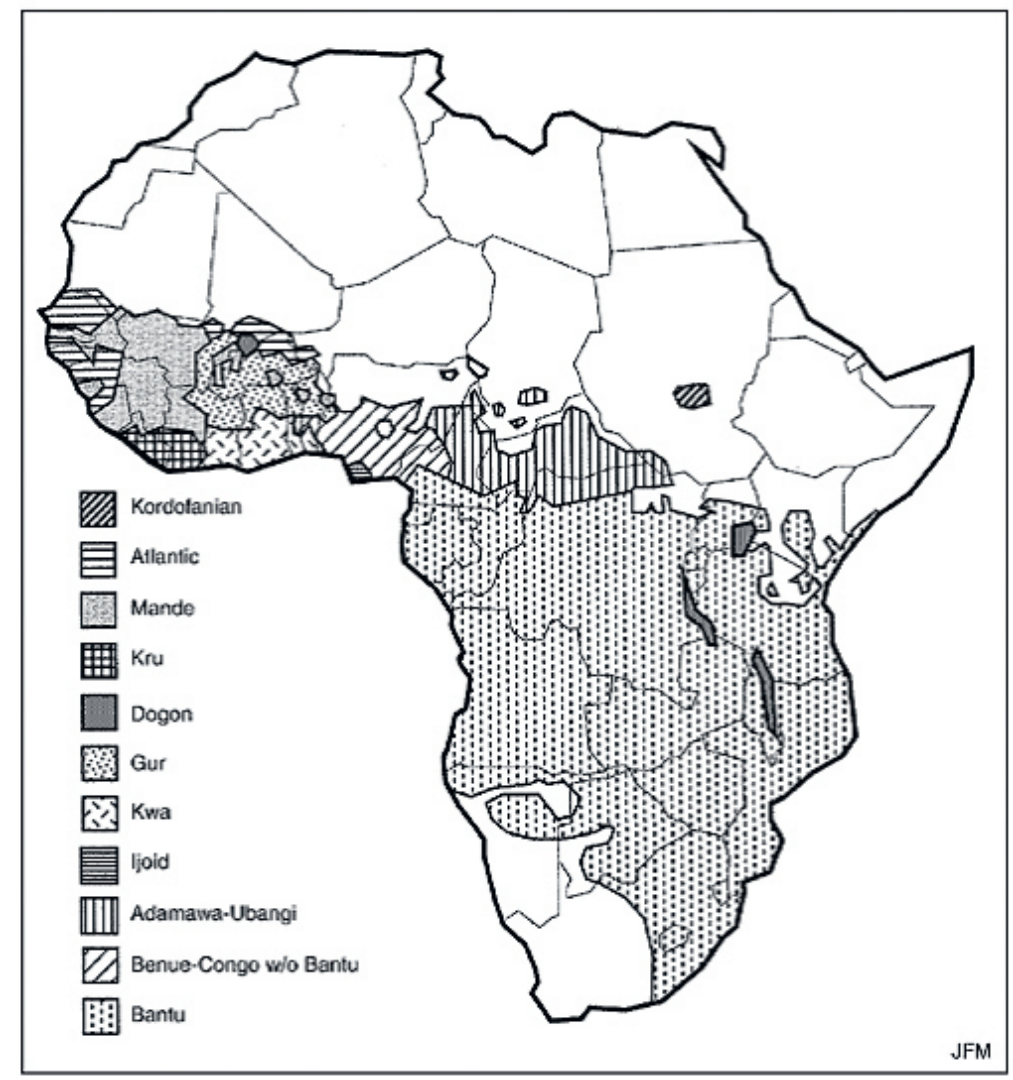

Figura 19.3 - Família niger-congo. Fonte: Nurse e Philippson (2003, p. 2).

O termo bantu, que designa os povos e as línguas, pode ser traduzido como "gente", "pessoas", "humanos" e tem sua origem na raiz lexical "ntu", com o prefixo da classe nominal 2 "ba", os quais são bastante recorrentes nas línguas da família bantu. Esse termo designativo foi inicialmente proposto por William Bleek (1862) e vem sendo, desde então, utilizado para se referir às línguas que pertencem à família linguística bantu. Destarte, tem sido ainda amplamente utilizado por linguistas, historiadores, antropólogos e por pesquisadores de outras áreas para nomear as línguas pertencentes ao subgrupo niger-congo B, conforme delineado na Figura 19.3.

A hipótese segundo a qual as línguas bantu são bastante aparentadas entre si pode ser comprovada pela percepção de que as diferenças entre elas são sempre 
regulares e sistemáticas. Essa sistematicidade e regularidade apontam para uma nítida derivação a partir de uma protolíngua comum. Tal situação descarta qualquer assunção de que as várias características mútuas entre essas línguas, tanto em níveis fonológicos, lexicais, morfológicos e sintáticos, são o resultado de mero acaso. As semelhanças inegáveis das línguas bantu podem ser notadas, por exemplo, pela ocorrência de prefixos que figuram nos substantivos das várias classes nominais. Esses afixos são recorrentes em todas as línguas pertencentes à família linguística bantu e exercem papel crucial nos vários sistemas de concordância que há no âmbito dos sintagmas nominais e verbais.

Também pode ser destacada a regularidade que há em relação à estrutura morfológica do verbo em todas as línguas bantu. Em geral, nessas línguas, o complexo verbal se constituiu como representado na Figura 18.4, a seguir (MEEUSSEN, 1967 apud LEACH, 2010, p. 86). Na reconstrução da estrutura verbal das línguas bantu de Meeussen (1967), o slot pré-inicial é ocupado pelo morfema negativo primário ou por conectivos de ligação empregados em orações adverbiais e relativas. Já o slot de concordância de sujeito é de fato considerado a parte inicial do campo flexional do verbo. O slot pós-inicial é geralmente ocupado pelo afixo que expressa o negativo secundário na língua. Por fim, a última posição no campo flexional é ocupada pela marcação de tempo e aspecto. Por sua vez, o tronco macro constitui os demais elementos da estrutura verbal como os paradigmas de concordância de objeto, a raiz verbal, a(s) extensão(ões) verbal(is) (como a extensão aplicativa, a extensão causativa, a extensão estativa etc.) e o formativo, slot este que pode ser ocupado por sufixos que indicam modo (indicativo, subjuntivo etc.) ou aspecto (perfectivo). 


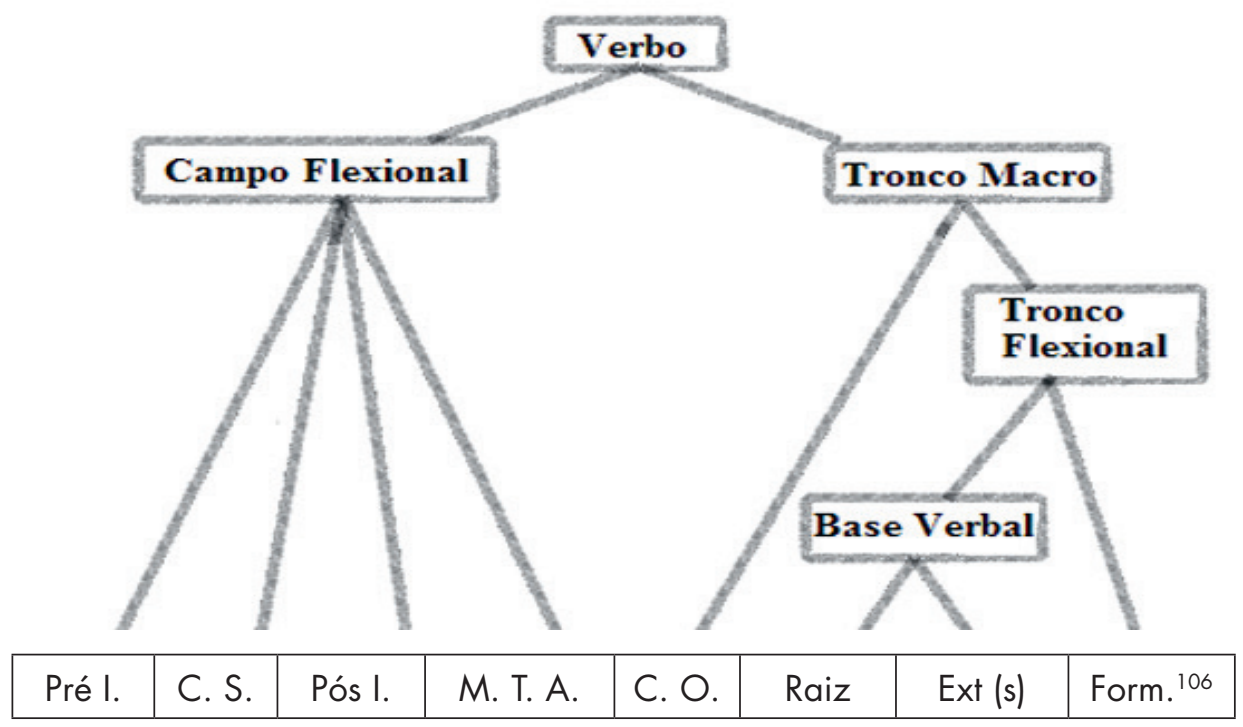

Os exemplos ${ }^{107}$ arrolados a seguir, retirados da língua shimakonde, buscam exemplificar a coocorrência dos prefixos possíveis nos vários slots descritos na Figura 18.4.

(1)

\begin{tabular}{|c|c|c|c|c|c|c|c|}
\hline$\ldots$ & $t u-$ & $\ldots$ & $-n d i-$ & $-v a-$ & $-t u k u t-$ & $\ldots$ & $-a$ \\
\hline \multicolumn{8}{|c|}{ tundivatukuuta "nós corremos deles" } \\
\hline
\end{tabular}

(2)

\begin{tabular}{|c|c|c|c|c|c|c|c|}
\hline$\ldots$ & $t u-$ & $\ldots$ & $\ldots$ & $-v a-$ & $-t u k u t-$ & $\ldots$ & -ile \\
\hline \multicolumn{8}{|c|}{ tuvatukutile "nós corremos deles" } \\
\hline
\end{tabular}

(3)

106 As abreviaturas no referido quadro e exemplos posteriores representam: Pré I.: lacuna pré-inicial; C. S.: prefixo de concordância de sujeito; Pós I.: lacuna pós-inicial; M. T. A.: morfema de tempo e aspecto; C. O.: concordância de objeto; Raiz: raiz verbal; Ext (s): extensões verbais; e Form.: formativo. 1p: primeira pessoa do plural; cn2: classe nominal 2; perf: perfectivo; pimp: passado imperfectivo; cn1cx: conectivo de classe nominal 1; neg: negativo; apl: aplicativo; v. f.: vogal final.

107 Esses dados foram retirados e adaptados a partir de Leach (2010, p. 86). 


\begin{tabular}{|c|c|c|c|c|c|c|c|}
\hline$a^{-}$ & $t u^{-}$ & $\ldots$ & $\ldots$ & $-v a^{-}$ & $-t u k u t-$ & $\ldots$ & -ile \\
\hline neg & $1 p$ & & & $\mathrm{cn} 2$ & correr & & perf \\
\hline \multicolumn{7}{|c|}{ atuvatukutile "nós não corremos deles" } \\
\hline
\end{tabular}

(4)

\begin{tabular}{|c|c|c|c|c|c|c|c|}
\hline$\ldots$ & vá- & Ká & $\ldots$ & - twaal- & $\ldots$ & $-a$ \\
\hline & $\mathrm{cn} 2$ & neg & & pegar & & v. f. \\
\hline \multicolumn{6}{|c|}{ vákátwaala "eles não vão pegar" } \\
\hline
\end{tabular}

(5)

\begin{tabular}{|l|c|c|c|c|c|c|c|}
\hline mwá- & tú- & $\ldots$ & shí- & $\ldots$ & Tángál & -él & $-a$ \\
\hline $\mathrm{cnl \textrm {lcx }}$ & $\mathrm{lp}$ & \multicolumn{1}{c|}{ pimp } & & falar & Apl & v. f. \\
\hline \multicolumn{3}{|c|}{ mwátúshítángálééla "o modo no qual nós estamos falando" } \\
\hline
\end{tabular}

Figura 19.4 - Estrutura verbal das línguas bantu.

Assim como historicamente as línguas românicas derivam do latim vulgar, podemos postular que as línguas bantu possuem uma língua ancestral comum. A diferenciação atual pode ser compreendida como sendo resultado de um longo processo de dispersão que ocorreu após períodos de distanciamento, aliados a fatores sociolinguísticos e culturais peculiares. Adicionalmente, contatos com outras línguas e culturas e características distintas de cada novo ambiente linguístico foram responsáveis por gerar a grande diversificação que há atualmente entre as línguas bantu. A grande extensão territorial, onde as línguas bantu são faladas, revela indícios muito fortes de um processo de expansão migratória que se teria desenrolado gradualmente desde épocas remotas. Nessa linha de investigação, Diamond e Bellwood (2003) argumentam que os grandes movimentos e mudanças de populações desde o fim das eras glaciais foram resultantes do incomum aumento da capacidade de produção alimentícia pelo mundo. Dessa forma, as primeiras comunidades agrícolas que surgiram na região dos povos bantu tiveram vantagens diferenciais em relação às populações que subsistiam da caça e coleta. Consoante Diamond e Bellwood (2003), há três principais vantagens dos povos agricultores em relação aos povos caçadores, a saber: (i) maior capacidade de produção de alimentos, já que o estilo de vida agrícola poderia fornecer melhores subsídios para o crescimento populacional, quando comparado com o estilo de 
subsistência baseado na caça e coleta; (ii) a produção local de alimentos permitia aos agricultores levar uma vida sedentária, pré-requisito fundamental para a posterior organização em cidades, a constituição de exércitos e o estabelecimento de uma estratificação social mais elaborada; e (iii) desenvolvimento de maior resistência a doenças infecciosas como a varíola e o sarampo, devido ao contato regular com animais domesticáveis responsáveis pela disseminação dos agentes patogênicos. Tendo em conta esses fatores, uma das principais hipóteses aventada por muitos pesquisadores é que a expansão bantu é engatilhada por uma mudança no modo de vida agrícola, o que, por sua vez, resulta em maior difusão linguística e cultural dos povos bantu. Sobre a expansão dos povos bantu, Posnansky (2010, p. 595) propõe o seguinte:

embora as origens, a época e o modo de desenvolvimento da agricultura africana sejam relativamente controversos, em geral se admite que, à exceção de certas comunidades rigorosamente localizadas no Rift Valley do Quênia, que teriam cultivado o milhete, o início da agricultura, pelo menos na maioria das regiões da África onde se fala o bantu, é contemporâneo do surgimento da metalurgia do ferro. Geralmente também se acredita que vários dos primeiros gêneros alimentícios básicos na África bantu, como a banana frutífera, a colocasia (inhame), a eleusine cultivada e o sorgo, foram introduzidos, em última instância, por meio da África ocidental, ou ainda, no caso da banana, indiretamente, pela Ásia do sudeste.

\section{Diversidade linguística em Moçambique}

Situada na costa oriental da região austral da África, a República de Moçambique tem as seguintes fronteiras geográficas: ao norte, faz divisa com a Tanzânia; ao noroeste, partilha fronteira com Malawi, Zâmbia e Zimbábue; ao sul, com África do Sul e Suazilândia; e ao sudeste e nordeste, é banhada pelo Oceano Índico. Dados de 2013 da Undesa ${ }^{108}$ aponta que Moçambique possui 24.366.000 habitantes. O país possui 129 distritos divididos em onze províncias, a saber: Niassa, Cabo Delgado, Nampula, Zambézia, Tete, Manica, Sofala, Inhambane, Gaza, Maputo e Maputo-cidade, conforme se vê pelo Figura 18.5, a seguir.

108 Conferir: <http://www.ethnologue.com/country/MZ>. 


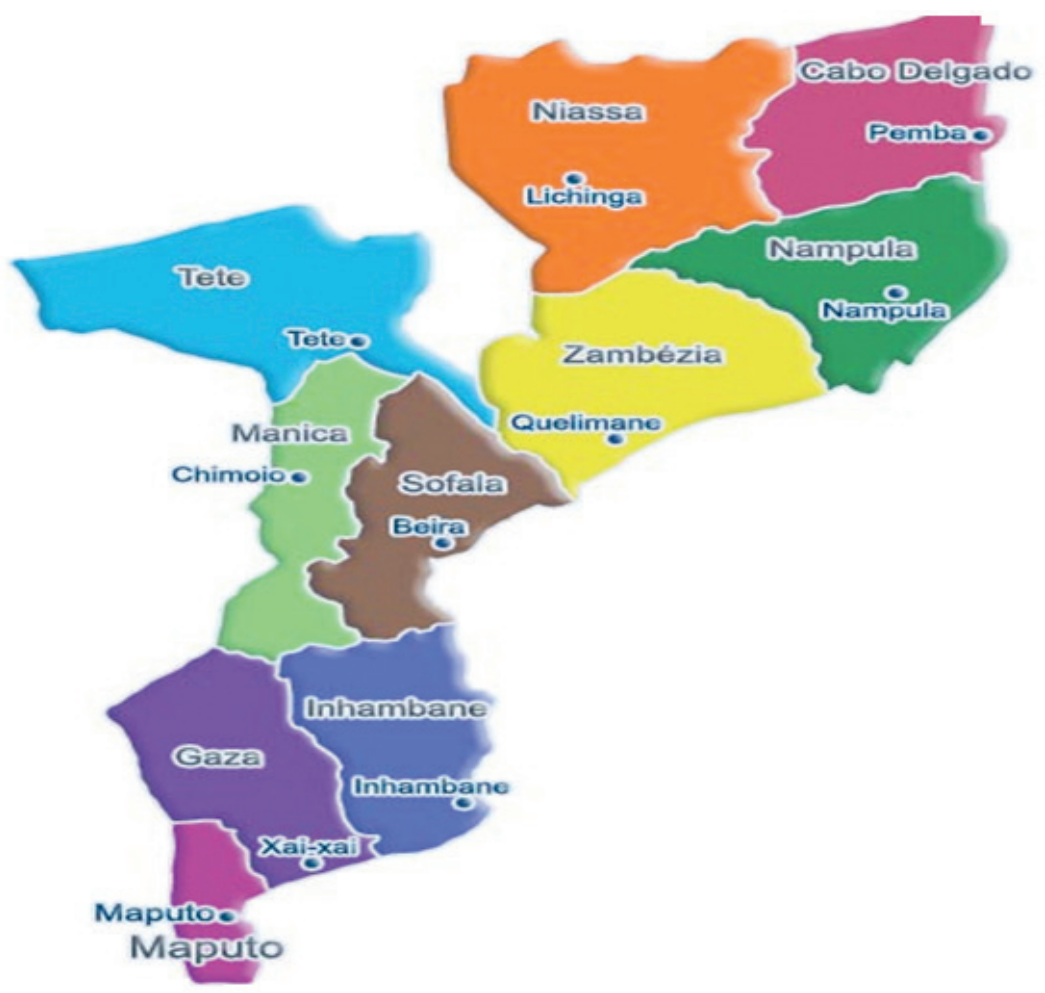

Figura 19.5 - Distribuicão geográfica das onze províncias Moçambicanas. Fonte: <https://gramadavizinha.files. wordpress.com/2011/12/mapa-mocambique.jpg >. Acesso em: 17 ago. 2016.

Conforme dados apurados a partir de Ngunga (2012, p. 3), podemos afirmar com certa segurança que a situação linguística nesse país é marcada pela existência de uma grande diversidade de povos e línguas. Nesse sentido, assim como a maioria dos países africanos, pode-se considerar que Moçambique é um país multilíngue, tendo em vista que coexistem com o português uma variedade de línguas nativas, todas pertencentes à família linguística bantu. Em consonância com Ngunga, Rego (2012) caracteriza o país com um mosaico de povos, culturas, religiões, etnias e línguas, resultado da convivência de vários povos autóctones (como khoi-khoi e san), oriundos da migração de povos bantu, persas (árabo-swahilis), árabes, indianos, chineses, portugueses, ingleses, franceses, belgas, dentre outros.

Ngunga considera ainda que as línguas bantu constituem o principal substrato linguístico do país, visto que essas são as línguas maternas de mais de oitenta por cento de moçambicanos. Ademais, os dados estatísticos sobre a situação 
linguística de Moçambique variam muito, dependendo da fonte a que se consulta, o que dificulta identificar quantas línguas são faladas efetivamente no país. Ngunga $(2011$, p. 180) nos fornece a seguinte tabela, para termos uma ideia geral sobre quão divergentes são essas fontes:

Tabela 19.2 - Número de línguas Moçambicanas.

\begin{tabular}{|c|c|c|}
\hline Fonte & Ano & No de línguas \\
\hline Cabral & 1975 & 15 \\
\hline Cardoso & 2005 & 25 \\
\hline Conselho Coordenador do Recenseamento & 1983 & 16 \\
\hline Firmino & 2000 & 24 \\
\hline Katupha & 1988 & 13 \\
\hline INE & 2010 & 21 \\
\hline Liphola & 2009 & 41 \\
\hline Lopes & 1999 & 20 \\
\hline NELIMO & 1989 & 20 \\
\hline Ngunga & 1987 & 33 \\
\hline Ngunga & 1992 & 21 \\
\hline Yai & 1983 & 13 \\
\hline
\end{tabular}

Fonte: Ngunga (2011, p. 180).

Curiosamente, quando se tenta responder à questão sobre o número exato de línguas faladas em Moçambique, o mais seguro, segundo Ngunga, é afirmar que o número total de línguas varia entre 9 e 43 . Ainda segundo o pesquisador, faz-se

urgente a realização de um recenseamento linguístico com base no qual se possa saber quantas línguas existem e quais as suas variantes, o que poderia permitir a elaboração de um atlas linguístico do país. Um tal estudo ajudaria também a esclarecer a problemática que há entre línguas e variantes, cuja falta de clareza parece favorecer a proliferação de línguas em Moçambique (NGUNGA, 2012, p. 3).

Na mesma direção, Rego (2012) alega que os principais motivos para a falta de consenso no número de línguas faladas em Moçambique residem em fatores como a falta de critérios de distinção entre língua e etnia, língua e grupo de línguas e língua e dialeto. A falta de trabalhos extensivos de descrição linguística, a pouca literatura existente nessas línguas, além da escassez de estudos dialetoló- 
gicos contribuem para um quadro de indefinição na quantidade exata de línguas faladas no país. O autor afirma que apenas recentemente se criou ambiente propício para a investigação das línguas bantu, principalmente por meio de iniciativa da Universidade Eduardo Mondlane (UEM) e do Núcleo de Estudos em Línguas Moçambicanas (Nelimo) e outros órgãos governamentais. Todavia, ainda há escasso número de linguistas dedicados às pesquisas em linguística bantu, o que poderia ser atestado pela averiguação do maior número de trabalhos dedicados à língua portuguesa que são conduzidos na universidade.

Apesar das discrepâncias apontadas na Tabela 19.2, dados oficiais, apurados a partir do recenseamento geral da população realizado em 2007 e divulgados em 2010 pelo Instituto Nacional de Estatística de Moçambique, sugerem que são faladas em Moçambique 22 línguas. A relação completa de cada uma dessas línguas é apresentada na Tabela 19.3, a seguir.

Tabela 19.3 - Línguas faladas pela população de 5 ou mais anos de idade.

\begin{tabular}{|c|c|c|c|c|}
\hline$N^{\circ}$ & Línguas & Falantes & $\%$ & Províncias onde são faladas \\
\hline 1 & Makhuwa & 4.105 .122 & 25.92 & $\begin{array}{c}\text { Cabo Delgado, Nampula, Niassa, } \\
\text { Zambézia, Sofala }\end{array}$ \\
\hline 2 & Português & 1.828 .239 & 11.54 & Todas as províncias \\
\hline 3 & Changana & 1.682 .438 & 10.62 & $\begin{array}{c}\text { Gaza, Maputo, Maputo City, Inham- } \\
\text { bane, Niassa }\end{array}$ \\
\hline 4 & Sena & 1.314 .190 & 8.30 & Manica, Sofala, Tete, Zambézia \\
\hline 5 & Lomwe & 1.202 .256 & 7.59 & Nampula, Niassa, Zambézia \\
\hline 6 & Chuwabu & 989.579 & 6.24 & Sofala, Zambézia \\
\hline 7 & Nyanja & 905.062 & 5.71 & Niassa, Tete, Zambézia \\
\hline 8 & Ndau & 702.455 & 4.43 & Manica, Sofala \\
\hline 9 & Tshwa & 469.343 & 2.96 & Gaza, Inhambane, Maputo, Sofala \\
\hline 10 & Nyungwe & 457.290 & 2.88 & Manica, Tete \\
\hline 11 & Yaawo & 340.204 & 2.14 & Cabo Delgado, Niassa \\
\hline 12 & Makonde & 268.450 & 1.69 & Cabo Delgado \\
\hline
\end{tabular}




\begin{tabular}{|c|c|c|c|c|}
\hline 13 & Tewe & 255.704 & 1.61 & Manica \\
\hline 14 & Rhonga & 239.333 & 1.52 & $\begin{array}{c}\text { Gaza, Maputo, Cidade de Maputo, } \\
\text { Inhambane }\end{array}$ \\
\hline 15 & Tonga & 203.924 & 1.28 & $\begin{array}{c}\text { Gaza, Inhambane, Maputo, Cidade } \\
\text { de Maputo }\end{array}$ \\
\hline 16 & Copi & 169.811 & 1.07 & $\begin{array}{c}\text { Gaza, Inhambane, Maputo, Cidade } \\
\text { de Maputo }\end{array}$ \\
\hline 17 & Manyika & 133.190 & 0.84 & Manica \\
\hline 18 & Cibalke & 102.778 & 0.64 & Manica \\
\hline 19 & Mwani & 77.915 & 0.49 & Cabo Delgado \\
\hline 20 & Koti & 60.780 & 0.38 & Nampula \\
\hline \multirow[t]{4}{*}{21} & Swahili & 15.250 & 0.10 & Cabo Delgado \\
\hline & Outras LM & 310.259 & 1.95 & Todas as províncias \\
\hline & $\begin{array}{l}\text { Línguas dos } \\
\text { sinais }^{108}\end{array}$ & 7.059 & 0.05 & Todas as províncias \\
\hline & Total & $15.833 .572^{109}$ & 100 & Todas as províncias \\
\hline
\end{tabular}

Fonte: INE (2010).

As línguas moçambicanas estão distribuídas em diferentes zonas linguísticas, de acordo com a classificação de Guthrie (1967-1971), a saber: zona G, zona P, zona N e zona S. A proposta de Guthrie (1967-1971) para a classificação das línguas bantu está representada na Figura 19.6, a seguir.

109 No original dos dados do Censo são chamadas "línguas dos mudos”. Geralmente designa no plural por que ainda não estão sistematizadas nem padronizadas.

110 Moçambique tem atualmente (2012) cerca de 23.000.000 habitantes. 


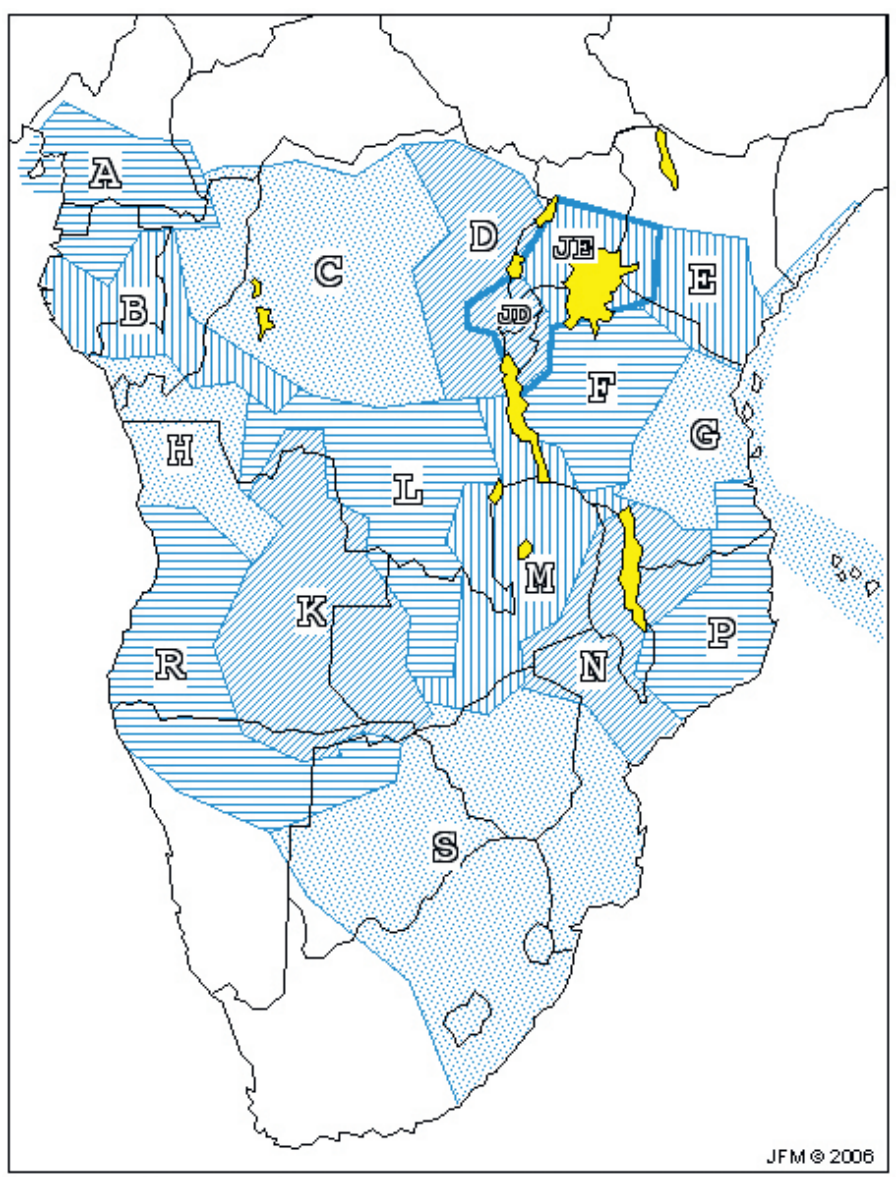

Figura 19.6 - Línguas bantu: classificação referencial de Guthrie. Fonte: <http://goto.glocalnet.net/ maho/00images/map_bantu.gif>.

Aqui se faz pertinente tecer alguns comentários sobre essa classificação. A proposta de Guthrie é bastante difundida e utilizada entre os linguistas. Está organizada por áreas cujas línguas representam certa uniformidade ou similaridade de fenômenos linguísticos. São representadas por letras maiúsculas e um código numérico de dois a três dígitos, os quais têm a função de sinalizar a que grupo linguístico determinada língua pertence. A esse código de três ou quatro dígitos ainda pode ser acrescentada uma letra minúscula ao final para indicar um dialeto de alguma língua específica. Para um conhecimento mais acurado dessa classificação, tomemos como exemplo a classificação da língua makonde e de outras línguas que estão na mesma zona linguística, conforme indica a Figura 19.7, a seguir: 


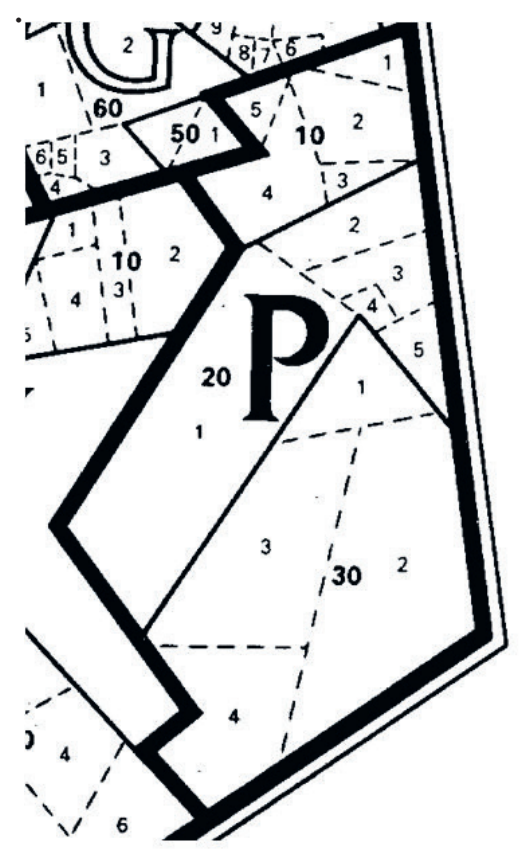

\section{P.11 Ndengereko \\ P.12 Ruihi \\ P.13 Matumbi \\ P.14 Ngindo \\ P.15 Mbunga}

P.21 Yao

P.22 Mwera

P.23 Makonde

P.24 Ndonde

P.25 Mabiha

\section{P.31 Makua}

P.32 Lomwe

\section{P.33 Ngulu}

\section{P.34 Cuabo}

Figura 19.7 - Distribuiç̃ó das línguas da zona P conforme classificação de Guthrie. Fonte: Adaptado de <http:// www.bantu-languages.com/zone_p.html>.

Note que a língua makonde recebe a sigla P.23. Podemos ainda perceber que a zona P está dividida em três grandes áreas distintas: 10, 20 e 30. Essas regiões possuem línguas aparentadas entre si e são codificadas por um número (que, dependendo da variedade linguística de cada região, pode ser de um ou dois dígitos). Assim, o makonde é falado na região 20, especificamente na área representada pelo número 3 dentro dessa região.

Rego (2012), por sua vez, propõe o mapa da Figura 19.8, de autoria de Oliver Kröger. Nele, especifica-se como as zonas linguísticas e grupos linguísticos propostas por Guthrie estão distribuídas pelo país. Nesse mapa panorâmico, constam as zonas de Guthrie e seus grupos devidamente numerados, o qual se constitui de uma lista numerada por ordem alfabética das línguas moçambicanas.

Em termos práticos, devido à sua importância, Rego argumenta que as línguas changana (língua franca falada na região sul), sena (língua franca falada no centro do país) e makhuwa (língua franca falada na região norte) figurariam como ótimas candidatas a receber o estatuto de línguas oficiais do país juntamente com a língua portuguesa. $\mathrm{O}$ mapa abaixo apresenta as principais zonas linguísticas que estão presentes no território moçambicano. 


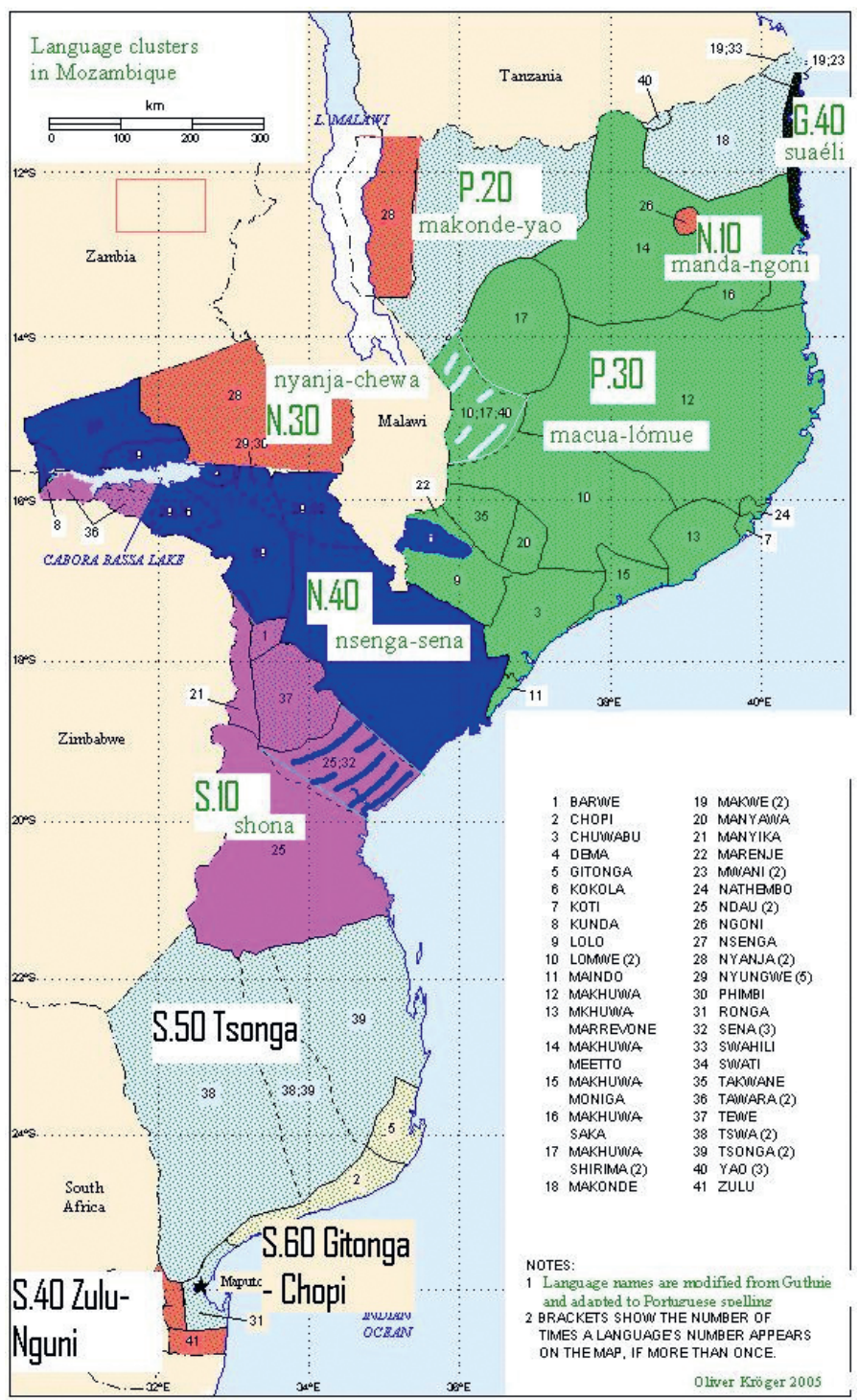

Figura 19.8 - Mapa de zonas linguísticas de Moçambique. Fonte: KRÖGER (2005) apud REGO (2012), p. 17.

Umas das características mais salientes das línguas bantu é a classificação dos substantivos das línguas em diferentes classes nominais. Cada classe nominal é regida por um prefixo próprio (geralmente uma classe nominal ímpar forma seu plural com a classe par seguinte). Esses prefixos são responsáveis por desencadear uma série de paradigmas de concordância na gramática das línguas. O quadro da Figura 19.9, a seguir, apresenta as classes nominais que são recorrentes em treze línguas moçambicanas: 


\begin{tabular}{|c|c|c|c|c|c|c|c|c|c|c|c|c|c|}
\hline Classe & $\stackrel{3}{\Xi}$ & $\stackrel{\vec{g}}{\bar{g}}$ & 产 & 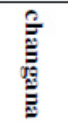 & 高 & 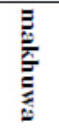 & $\begin{array}{l}\bar{\sigma} \\
\underline{g} .\end{array}$ & 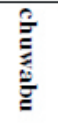 & 忢 & 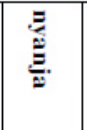 & 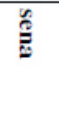 & 产 & 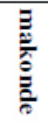 \\
\hline 1 & $m u-$ & $m u-$ & $m u-$ & $m u-$ & $m u-$ & $m u-$ & $m u-$ & $m u-$ & mu- & $m u-$ & $m u-$ & $m u-$ & $m u-$ \\
\hline 2 & $v a-$ & $v b a-$ & $v a-$ & $v a-$ & $v a-$ & $a-$ & $a-$ & $a-$ & wa-/a- & $w a-/ a-$ & $a-$ & $\begin{array}{c}\text { a- } \\
\text { iva- }\end{array}$ & $v a-$ \\
\hline 3 & $m u-$ & $m u-$ & $m u-$ & $m u-$ & $m u-$ & $m u-$ & $m u-$ & $m u-$ & $m u-$ & $m u-$ & $m u-$ & $m u-$ & $m u-$ \\
\hline 4 & $m i-$ & $m i-$ & $m i-$ & $m i-$ & $m i-$ & $m i-$ & $m i-$ & $m i-$ & $m i-$ & $m i-$ & $m i-$ & $m i-$ & $m i-$ \\
\hline 5 & $d i-$ & li- & li- & $l i-/ r i-$ & li- & $n i-$ & $n i-$ & $n i-$ & li-/di- & li- & li- & di- & li- \\
\hline 6 & ma- & ma- & ma- & ma- & ma- & ma- & ma- & ma- & ma- & ma- & ma- & ma- & ma- \\
\hline 7 & $c i-$ & $g i-$ & $x i-$ & $x i-$ & $c i-/ x i-$ & $e-$ & $e-$ & $e-$ & $c i-$ & $c i-$ & $c i-$ & $c i-$ & $s h i-$ \\
\hline 8 & si- & si- & svi- & svi- & $\mathrm{zvi}-$ & $i-$ & $i-$ & $i-$ & bzwi- & $z i-/ v i-$ & $p i-$ & $v i-$ & $v i-$ \\
\hline 9 & N- & $\mathrm{N}-$ & $\mathrm{N}-$ & N- & $\mathrm{N}-$ & - & $\varnothing$ & $\mathrm{N}-$ & $\mathrm{N}-$ & $\mathrm{N}-$ & $\mathrm{N}-$ & $\mathrm{N}-$ & $\mathrm{N}-$ \\
\hline 10 & $t i-$ & $\begin{array}{c}(d z i-)) \\
\mathrm{N}-\end{array}$ & N- & N- & $\mathrm{N}-$ & - & $\varnothing$ & $\mathrm{N}-$ & N- & N- & N- & N- & $d i-$ \\
\hline 11 & - & - & li- & li- & li- & - & - & - & - & - & - & $l u-$ & lu- \\
\hline 12 & - & - & - & - & - & - & - & - & ka- & $\mathrm{ka}-$ & $k a-$ & $k a-$ & ka- \\
\hline 13 & - & - & - & - & - & - & - & - & $t u-$ & $t u-$ & $t u-$ & $t u-$ & $t u-$ \\
\hline 14 & $u$ - & $w u-$ & (v)u- & $w u-$ & $u-$ & $o-$ & $o-$ & $o-$ & $u$ - & $u$ - & $u-$ & $w u-$ & $w u-$ \\
\hline 15 & $k u-$ & $g u-$ & $k u-$ & $k u-$ & $k u-$ & $o-$ & $o-$ & $o-$ & $k u-$ & $k u-$ & $k u-$ & $k u-$ & $k u-$ \\
\hline 16 & ha- & ha- & ha- & ha- & ha- & $v a-$ & $v a-$ & $v a-$ & $p a-$ & $p a-$ & $p a-$ & $p a-$ & $p a-$ \\
\hline 17 & $k u-$ & $g u-$ & $k u-$ & $k u-$ & $k u-$ & $o-$ & $o-$ & $o-$ & $k u-$ & $k u-$ & $k u-$ & $k u-$ & $k u-$ \\
\hline 18 & $m u-$ & $m u-$ & $m u-$ & $m u-$ & $m u-$ & $m u-$ & $m u-$ & $m u-$ & $m u-$ & $m u-$ & $m u-$ & $m u-$ & $m u-$ \\
\hline 21 & & & $j i-$ & ji- & & & & & & & & & \\
\hline
\end{tabular}

Figura 19.9 - Quadro com prefixos das classes nominais de línguas moçambicanas. Fonte: Sitoe e Ngunga (2000, p. 120 apud REG0, 2012, p. 48).

A hipótese corrente é que as classes nominais possuem motivações semânticas, que remontam ao protobantu. Rego (2012) aponta que as classes nominais 1 e 2 geralmente se referem a seres humanos, personificados ou divinizados, nomes próprios, termos de parentesco etc. Já as classes nominais 3 e 4 geralmente reúnem designações de plantas, árvores e objetos diversos. As classes 5 e 6 referem-se à designação de partes do corpo humano, animais domésticos, frutos, portuguesismos, nomes não contáveis e termos de parentesco. Por sua vez, as classes 7 e 8 agrupam conjuntos de coisas, coisas pontiagudas, objetos e referências a aumentativos e a depreciativos. As classes 9 e 10 compreendem nomes atribuídos a objetos diferenciados, animais domésticos, nomes diversos, exceções e portuguesismos. Já as classes 12 e 13 se referem a diminutivos. A classe 14 consiste de nomes abstratos, não contáveis, objetos de uso corrente e partes do corpo. Já a classe 15 inclui o infinitivo verbal e as classes 16 a 18 denotam diferentes tipos de locativos. Os pares 1/2, 3/4, $5 / 6$ e 7/8 e as classes 15 a 18 são as classes mais comuns entre as línguas bantu. 


\section{Considerações finais}

A diversidade linguística sugerida pelos dados acima aponta para a urgente necessidade de pesquisas voltadas para as línguas nativas de Moçambique, uma vez que mais da metade dessas línguas ainda carece de descrições gramaticais bem detalhadas. Essa situação se deve ao fato de os estudos linguísticos não terem sido prioridade durante o período colonial, o que explica a escassez de materiais sobre as línguas nacionais. Em suma, nota-se que há uma lacuna que precisa ser preenchida em relação à descrição, documentação e valorização das línguas moçabicanas. Nesse sentido, Ngunga (2008 apud REGO, 2012, p. 15, tradução nossa) observa o seguinte:

a diplomacia internacional, as negociações com outras pessoas podem ser realizadas em qualquer idioma, mas a linguagem de desenvolvimento de qualquer povo é a sua própria língua. Não se admira que depois de muitos anos de uso do latim e do grego como línguas de Ciência nas universidades, os europeus decidiram adotar suas próprias línguas. Foi sob esse movimento que a Alemanha decidiu no século XVIII a mudar a partir dessas línguas para a sua própria língua, o alemão. Assim, Os Africanos e seus amigos precisam investir em educação através das línguas que as crianças africanas já falam simplesmente porque ninguém vai para a lua como uma expedição científica em uma linguagem emprestada, ninguém na Terra se desenvolve sem desenvolver sua própria língua. ${ }^{111}$

É por essa razão que recentemente pesquisadores da UFMG e da Universidade Eduardo Mondlane vêm envidando esforços para um trabalho conjunto no intuito de promovermos a elaboração de gramáticas descritivas, dissertações de doutorado e de mestrado, artigos científicos sobre as línguas bantu faladas em Moçambique, dentre outros materiais de documentação. O objetivo é preencher a lacuna existente em relação ao trabalho linguístico com essas línguas. Resultados recentes dessa parceria podem ser acessados no portal recentemente lançado pelo Laboratório de Línguas Indígenas e Africanas da Faculdade de Letras da UFMG, cujo endereço é www.letras.ufmg.br/portal laliafro.

111 The international diplomacy, the negotiations with other people can be undertaken in any language, but the language of development of any people is their own language. No wonder why after many years of use of Latin and Greek as languages of Science in the universities, the Europeans decided to adopt their own languages. It was under this movement that Germany decided in XVIII century to shift from those languages to their own language, the Deutch. So, the African and their friends need to invest in education through the languages the African children already speak simply because nobody goes to the moon as a scientific expedition in a borrowed language, no people on the earth will be developed without developing their own language (NGUNGA, 2008 apud REGO, 2012, p. 15). 


\section{Referências}

BLEEK, W. H. I. A comparative grammar of south african languages - part 1: phonology. Cape Town: J. C. Juta; London: Trübner \& Co., 1862.

- A comparative grammar of south african languages - part 2: the concord. Cape Town: J. C. Juta; London: Trübner \& Co., 1869.

CHILDS, G. T. An introduction to african languages. Philadelphia: John Benjamin's, 2003.

CRYSTAL, D. The Cambridge encyclopedia of language. Cambridge: Cambridge University Press, 1995.

DIAMOND, J.; BELLWOOD P. Farmers and their languages: the first expansions. Science 300, p. 596-603, 2003.

DUARTE, F. B. Tense encoding, agreement patterns, definiteness and relativization strategies in Changana. In: BOKAMBA, E. G. et al. (Ed.). Selected proceedings of the 40th annual conference on african linguistics. Somerville: Cascadilla Proceedings Project, p. 80-94, 2011.

GREENBERG, J. H. The languages of Africa. Indiana: Indiana Univ., 1966.

- Classificação das línguas da África. In: KI-ZERBO J. (Ed.). História geral da África I - metodologia e pré-história da África. 2. ed. Brasília, DF: Unesco, 2010. p. 317-336.

GUTHRIE, M. Comparative Bantu: an introduction to the comparative linguistics and prehistory of the Bantu languages. Farnborough: Gregg International, 1967-1971. v. 4.

KRÖGER, O. Algumas notas gramaticais sobre a lingua emakhuwa. Nampula: Sociedade Internacional de Linguística, 2005.

LEACH, M. B. Things hold together: foundations for a systemic treatment of verbal and nominal tone in Plateau Shimakonde. 2010. Dissertação (Doutorado) - Universiteit Leiden. Leiden, 2010. 435 p.

LOPES, A. J. Política linguística: princípios e problemas. Maputo: Universidade Eduardo Mondlane, 1997.

LWANGA-LUNYIIGO, S.; VANSINA, J. Os povos falantes de Bantu e sua expansão In: EL FASI, M.; HRBEK, L. (Ed.). História geral da África III: África do século VII ao XI. 2. ed. Brasília, DF: Unesco, 2010. p. 169-196.

MEEUSSEN, A. Bantu grammatical reconstructions. Africana Linguística, Tervuren, v. 61, n. 3, p. 79-121, 1967.

NGUNGA, A. 2012. “Os desafios da investigação linguística em África: o caso de 
Moçambique”. In: A Pesquisa na Universidade Africana no Contexto da Globalização: Perspetivas Epistemológicas Emergentes, Novos Horizontes Temáticos, Desafios. São Paulo: CEA-USP.

. Monolingual education in a multilingual setting: the case of Mozambique. Journal of Multicultural Discourses, v. 6, n. 2, 177-196, 2011. . 2008. "The role of african languages in the development of the continent". In: Special WOCAL 6 - World Congress of African Linguistics. São Paulo, p. 11-15, 2008. . Introdução à linguística Bantu. Maputo: Universidade Eduardo Mondlane, 2004.

NURSE, D.; PHILIPPSON, G. The Bantu languages. London: Routledge, 2003.

PAULA, R. R. Aspectos de morfossintaxe shimaconde. 2015. Dissertação (Mestrado em Estudos Linguísticos) - UFMG, 2016. 180 p.

POSNANSKY, M. Introdução ao fim da pré-história na África subsaariana. In:

MOKHTAR, G. (Ed.). História geral da África II - África antiga. 2. ed. Brasília, DF: Unesco, 2010. p. 585-606.

REGO, S. V. Descrição sistêmico-funcional da gramática do modo oracional das orações em Nyungwe. 2012. Dissertação (Doutorado) - Universidade de Lisboa, Lisboa, 2012.

SITOE, B.; NGUNGA A. (Org.). Relatório do II seminário sobre a padronização da ortografia de línguas moçambicanas. Maputo: Universidade Eduardo Mondlane, 2000. 